\title{
Evaluation of a novel membrane bioreactor system for water reuse applications in urban environments
}

\author{
R. R. Sharp ${ }^{1}$, G. Heslin ${ }^{2} \&$ M. Dolphin ${ }^{3}$ \\ ${ }^{I}$ Department of Civil and Environmental Engineering, \\ Manhattan College, Bronx, NY, USA \\ ${ }^{2}$ Malcolm Pirnie, Baltimore, MD, USA \\ ${ }^{3}$ Rockland County Sewer District \#1, Rockland, NY, USA
}

\begin{abstract}
A comprehensive pilot study was carried out to evaluate a small-foot print, high efficiency biological membrane wastewater treatment process to produce reuse quality water to address water shortages and continued development in a United States Federally designated sole source aquifer area. The treatment process included a high-rate primary settling unit with coagulant enhanced settling and phosphorous removal, followed by four-stage BNR membrane filtration. The goals of the study included: 1) determine if and under what operating conditions the MBR system could produce reuse quality water from a weak municipal wastewater; 2) determine the effects of coagulant addition on MBR performance and fouling; and 3) perform an economic analysis to determine if the process is competitive with conventional treatment methods. The study included testing process control strategies and assessing the addition of coagulation to enhancing settling and nutrient removal. Tests on the system were carried out to determine operational variables and requirements during high flow rates, ammonia challenges, cold and wet weather conditions, low BOD and nutrient loads, and biological upsets.
\end{abstract}

Keywords: membrane bioreactor, water reuse, wet weather, operational variable, fouling, biological nutrient removal, urban wastewater flows. 


\section{Introduction}

\subsection{Water reuse}

Advanced wastewater treatment technologies, wastewater reduction and water recycling initiatives, are considered the most practical water conservation strategies available at present [1]. Reuse is becoming the popular alternative in responsible wastewater treatment and water resource management. Emerging technologies, such as membrane bioreactors (MBR), can produce a reuse quality effluent that has direct and indirect reuse applications. Direct reuse is defined by Asano [2] as the use of reclaimed wastewater that as been transported from a wastewater reclamation plant to the water reuse site without intervening discharge to a natural body of water (e.g. agriculture, landscape irrigation and recreation). Indirect reuse is the use of wastewater reclaimed indirectly by passing it through a natural body of water or groundwater water aquifer (recharge) to supplement water resources in a particular watershed [2]. Nonpotable water recycling has proven to be successful in creating new and reliable water sources, and is a practice that continues to grow. The uses of recycled water are expanding to accommodate the needs of the environment and growing water supply demands. Advances in wastewater treatment technology and health studies of indirect potable reuse have led to an increase in planned indirect reuse worldwide [2].

While water recycling is a sustainable approach and can be cost-effective in the long term, the treatment of wastewater for reuse and the installation of distribution systems can be initially expensive compared to imported water or ground water. Institutional barriers can make it difficult to implement waterrecycling projects. However, water reuse has been used extensively in Japan and the U.K. and has grown immensely on the west coast and arid southwest of the United States [3, 4]. In addition to providing a dependable, locally controlled water supply, water recycling provides environmental benefits for the consumer, the economy and the eco-system. Reuse expands business and employment opportunities, and can cost $40 \%$ less than potable water [5]. Savings can be realized by communities, industries and agriculture to alleviate other cost increases, including the increase in potable water rates. If the reuse of water allows water to be treated to a lesser standard, treatment costs associated with upgrades or new plant construction may also be reduced [6].

\subsection{Reuse standards}

In the United States, the Environmental Protection Agency [7] provides the industry with guidelines for reuse quality effluent. An important distinction between conventional wastewater treatment $\left(\mathrm{BOD}_{5}, \mathrm{TSS}\right.$, Turbidity, and TKN) and production of reuse quality effluent is the requirement for removal of pathogens and metals, as well as greater reductions in nitrogen and phosphorous [8]. In the US, California has been the leader in establishing reuse criteria. For this study, a specific set of indirect reuse standards were developed as effluent 
quality goals shown in Table 1. Strict standards, such as those depicted in Table 1 are difficult to attain using conventional wastewater treatment methods, thus the need for improved technologies such as membrane bioreactors.

Table 1: $\quad$ Proposed wastewater effluent quality goals.

\begin{tabular}{|l|c|}
\hline \multicolumn{1}{|c|}{ Parameter } & Effluent Quality Goals \\
\hline BOD $_{5}(\mathrm{mg} / \mathrm{L})$ & $<3$ \\
\hline Total Suspended Solids $(\mathrm{mg} / \mathrm{L})$ & $<3$ \\
\hline Total Kjeldahl Nitrogen $-\mathrm{N}(\mathrm{mg} / \mathrm{L})$ & $<3$ \\
\hline Ammonia, $\mathrm{NH}_{3}-\mathrm{N}(\mathrm{mg} / \mathrm{L})$ & $<1$ \\
\hline Nitrite-N $(\mathrm{mg} / \mathrm{L})$ & 0 \\
\hline Nitrate-N $(\mathrm{mg} / \mathrm{L})$ & $2-4$ \\
\hline Total Nitrogen $(\mathrm{mg} / \mathrm{L})$ & $5-8$ \\
\hline Total Phosphate, $\mathrm{P}(\mathrm{mg} / \mathrm{L})$ & $0.2^{(1)}$ \\
\hline Fecal Coliforms $(\mathrm{no} / \mathrm{l} / 00 \mathrm{~mL})$ & $200 / 100$ \\
\hline Total Coliforms, MPN $(\mathrm{no} / 100 \mathrm{~mL})$ & $2400 / 100$ \\
\hline Settleable Solids $(\mathrm{mL} / \mathrm{L})$ & $<0.1$ \\
\hline Giardia Cysts & $99.9 \%$ removal $^{(1)}$ \\
\hline Enteric Viruses & $99.99 \%$ removal $^{(1)}$ \\
\hline Turbidity $(\mathrm{NTU})$ & $0.5-3.0$ \\
\hline Aluminum $(\mathrm{mg} / \mathrm{L})$ & $0.1^{(3)}$ \\
\hline Iron $(\mathrm{mg} / \mathrm{L})$ & $0.3^{(3)}$ \\
\hline Manganese $(\mathrm{mg} / \mathrm{L})$ & $0.3^{(3)}$ \\
\hline Copper $(\mathrm{mg} / \mathrm{L})$ & $0.0085^{(3)}$ \\
\hline Zinc $(\mathrm{mg} / \mathrm{L})$ & $0.078^{(3)}$ \\
\hline Amenable Cyanide $(\mathrm{mg} / \mathrm{L})$ & $0.0052^{(3)}$ \\
\hline Total Mercury, Hg $(\mathrm{mg} / \mathrm{L})$ & $0.0007^{(3)}$ \\
\hline
\end{tabular}

\subsection{Membrane Bioreactor Processes (MBR)}

Membrane bioreactors (MBRs) are quickly becoming the preferred wastewater treatment technology for public and private entities that have strict discharge requirements, limited water resources and/or a need for reuse quality water [9]. Growth of the MBR technology has been driven by the very high quality effluent produced by MBRs and their small footprint. MBRs are capable of meeting strict standards and are ideal for reuse applications for small to medium flows. The increasing interest in MBRs is fuelled not only by stricter effluent standards, but also by a steady reduction in the costs associated with membrane treatment, and improvements in membrane productivity and durability [10].

Use of MBRs for phosphorous removal has also been studied showing excellent phosphorous removal at a competitive price when compared with conventional methods $[11,12]$. The type of membranes used in wastewater 
treatment applications are micro-membranes, which have a larger nominal pore size than membranes used in drinking water treatment. The use of MBRs precludes the need for secondary clarifiers and tertiary sand filters. MBRs typically operate at MLSS concentrations up to 6 times higher than conventional activated sludge (CAS). High biomass results in longer solids retention times and lower growth rates, resulting in less waste sludge. Immersed membrane technology over-comes many of the sludge handling and recycling issues that impact the performance of CAS systems, and increases the flexibility of the treatment process. Membrane filters effectively remove suspended solids, protozoa (Giardia and Cryptosporidium), bacteria and many viruses reducing the need for excessive disinfection. MBRs are capable of producing a low turbidity effluent that is ideal for UV disinfection, reducing disinfection by-products [11].

The goal of this study was to use a scale-up approach to evaluate the performance of a novel MBR treatment system for indirect reuse of an urban wastewater highly influenced by wet weather flows. The approach included jartest studies to select appropriate coagulants to enhance settling and improve nutrient removal; operation of a bench scale membrane bioreactor (Zenon ZeeWeed ${ }^{\circledR}$ ZenoGem) to evaluate impact of coagulant on membrane performance; and operation of pilot system consisting of a high-rate primary settling unit with coagulation to enhance settling and phosphorous removal, followed by 7,000 gallon four-stage biological nutrient removal membrane filtration unit. The main objectives of this study were: 1) to determine if the MBR system could consistently produce reuse quality water; and 2) determine impact of coagulant addition on membrane performance and fouling, and 3) determine if MBR processes can effectively be applied to treat a weak municipal wastewater with varying nutrient loads and significant temperature variations.

\section{Bench scale studies}

The initial studies included jar tests to select for the most appropriate coagulant to use in primary settling to remove solids and phosphorous, and a bench scale system to evaluate the impact of residual coagulant on membrane performance. The jar testing showed that of the twenty coagulants tested, ferric chloride, alum, and a commercially available cationic coagulant provided the best removal of solids and phosphorous (results not shown). These coagulants were then tested at the bench-scale to determine their impact on membrane performance and fouling.

Bench-scale tests were performed to determine the effect residual coagulant might have on the performance of the ultra-membranes. The bench-scale unit consisted of a primary clarifier followed by a 100-liter membrane bioreactor (MBR) unit leased from Zenon Inc (ZeeWeed ZenoGem). The bench system treated raw municipal wastewater at approximately 0.5 gallons $/ \mathrm{min}$. with a biomass of 7,000 mg/l MLSS, and a solids retention time of 30 days. Table 2 shows the average characteristics of the wastewater. Specific coagulant doses as determined in the jar test studies were applied to the influent wastewater for a period of 100 hydraulic residence times. Comparisons between the control MBR 
(no coagulant) performance and the MBR performance with various coagulant additions were made in duplicate. The system operated with 15-minute vacuum sequences followed by a short back-pulse sequence to clear the membrane of accumulated biosolids. Membrane performance was measured using standard water quality (BOD, turbidity), average and max membrane vacuum pressure during a cycle (VP - degree of membrane fouling), max and average back-pulse pressure (BP - cleaning pressure required per cycle), and rate of vacuum pressure increase during a cycle (VP rate - rate of membrane fouling).

Table 2: Average raw wastewater quality.

\begin{tabular}{|c|c|}
\hline Parameter & Average \\
\hline CBOD & $130 \mathrm{mg} / \mathrm{L}$ \\
\hline TSS & $228 \mathrm{mg} / \mathrm{L}$ \\
\hline Ammonia & $22 \mathrm{mg} / \mathrm{L}$ \\
\hline Phosphorous & $5.2 \mathrm{mg} / \mathrm{L}$ \\
\hline Alkalinity & $230 \mathrm{mg} / \mathrm{L}$ as CaCO3 \\
\hline
\end{tabular}

In general, addition of coagulant decreased the magnitude and rate of vacuum pressure throughout a cycle. The decrease was caused by "conditioning" of the activated sludge resulting in better membrane permeability. Positive impacts of residual coagulant on membrane performance are illustrated in Figure 1, which shows the effect of coagulant dose on the rate of membrane fouling. Results showed that all coagulants had a positive impact on membrane performance, reducing both average and max applied membrane VP by as much as $75 \%$. Independent of type of coagulant, the bench MBR system removed $98 \%$ of influent $\mathrm{BOD}_{5}, 99 \%$ of suspended solids and $93 \%$ of the ammonia in the raw wastewater. In addition, ferric chloride removed $85 \%$ of influent phosphorous. Ferric chloride was used in the pilot study.

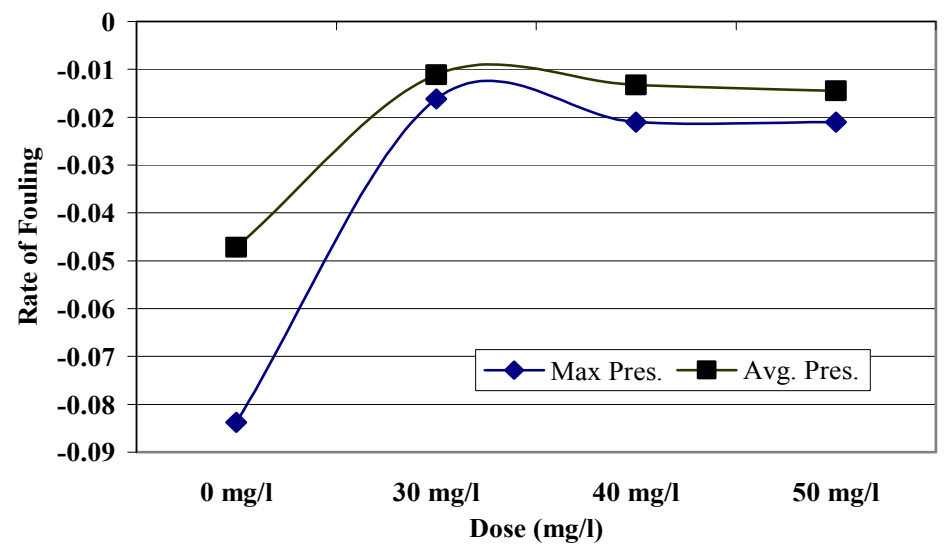

Figure 1: $\quad$ Rate of membrane fouling as a function of coagulant dose. 


\section{Pilot plant testing}

The pilot system included primary settling with coagulation to enhance settling and phosphorous removal, followed by a four-stage biological nutrient removal membrane filtration process (ZenoGem, Zenon, Toronto, Canada). Figure 2 is a schematic of the pilot treatment process. The pilot MBR system was operated at a flow rate of 54 liters per minute, a hydraulic residence time of 8.3 hours, a MLSS of $10,000 \mathrm{mg} / \mathrm{L}$, and a SRT of 30 days. Optimization of the pilot plant to meet reuse quality standards (Table 1) was carried out by maximizing the efficiency of each step of the nutrient removal process. This included optimization of dissolved oxygen zones, internal and external recycles flows, methanol addition, $\mathrm{pH}$ adjust and varying $\mathrm{F} / \mathrm{M}$ ratios. In addition, the impact of coagulation (ferric chloride) on pilot plant performance, phosphorous removal and membrane fouling were also evaluated.

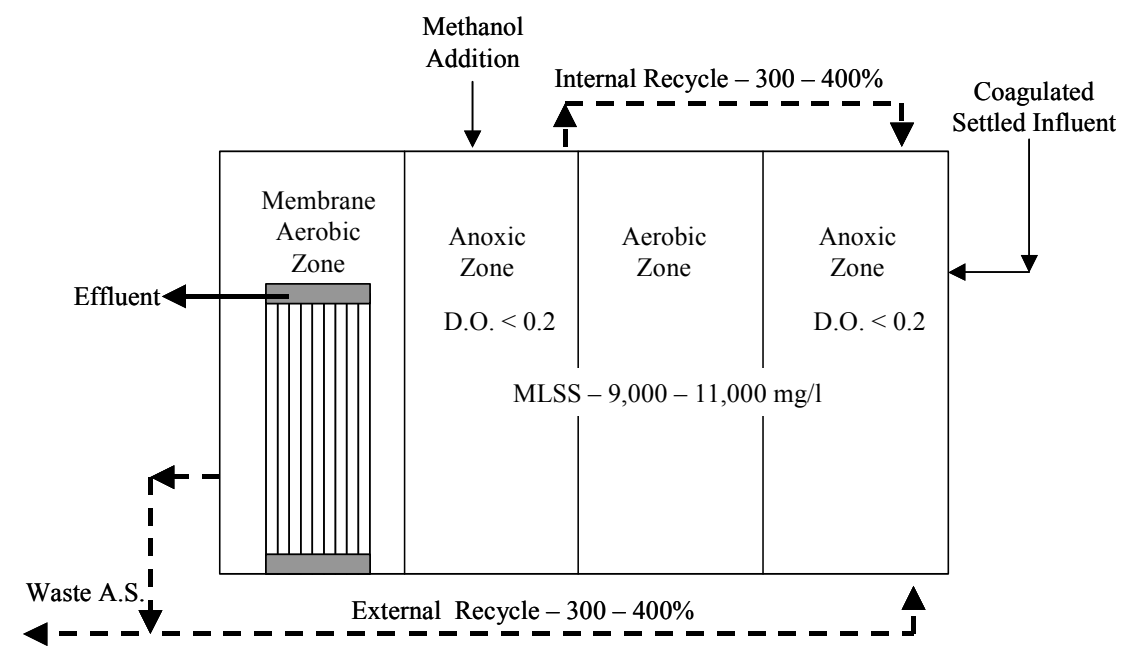

Figure 2: $\quad$ Schematic of Pilot MBR system.

\subsection{Performance summary}

The performance of the MBR system with full BNR is compared to typical values for conventional activated sludge (CAS) BNR performance in Table 3.

As can be seen the levels for BOD, ammonia, nitrate and total nitrogen are being met (see Table 1). The ferric chloride dose was optimized for phosphorous removal. With an increased ferric chloride dose and $\mathrm{pH}$ control, a phosphorous limit $0.2 \mathrm{mg} / \mathrm{l}$ could be reached. As expected the MBR system met the TSS and turbidity standards. Results also showed that the MBR system easily met the coliform $(<20 / 100 \mathrm{ml})$ and fecal coliform $(<3 / 100 \mathrm{ml})$ standards without disinfection. In addition, the effluent met all metal and cyanide standards and 99.99\% inactivation of viruses without disinfection (data not shown). 
Table 3: MBR performance compared to conventional activated sludge systems.

\begin{tabular}{|c|c|c|}
\hline Parameter & CAS & MBR \\
\hline SS, $\mathrm{mg} / \mathrm{l}$ & $<10$ & 0.6 \\
\hline BOD, $\mathrm{mg} / \mathrm{l}$ & $<5$ & 2 \\
\hline COD, $\mathrm{mg} / 1$ & $20-30$ & 21 \\
\hline Total $\mathrm{N}, \mathrm{mg} / 1$ & $<5$ & 6 \\
\hline NH3-N, mg/1 & $<2$ & 0.8 \\
\hline PO4 as $\mathrm{P}, \mathrm{mg} / 1$ & $<1$ & 0.1 \\
\hline Turbidity, NTU & $0.3-3$ & 0.3 \\
\hline
\end{tabular}

The pilot system encountered operational difficulties caused by temperature issues, BOD limitations, and flow capacity restrictions. Many of these issues are indicative of urban-type wastewater that tends to be weak (BOD $<120 \mathrm{mg} / \mathrm{l}$ ) and heavily influenced by wet weather flows.

Table 4: Operational parameters for conventional activated sludge systems compared to MBR performance during nutrient removal.

\begin{tabular}{|c|c|c|c|c|}
\hline Parameter & Units & CAS & $\begin{array}{c}\text { MBR } \\
\text { (Nite only) }\end{array}$ & $\begin{array}{l}\text { MBR (N \& P } \\
\text { removal) }\end{array}$ \\
\hline HRT & $\mathrm{Hr}$ & $4-8$ & 8.3 & 8.3 \\
\hline $\mathrm{F} / \mathrm{M}$ & 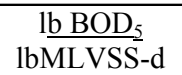 & $0.2-0.5$ & \multicolumn{2}{|c|}{$3.39 \mathrm{E}-02$} \\
\hline MLSS & $\mathrm{Mg} / \mathrm{l}$ & 2,000 & 10,000 & 10,000 \\
\hline $\begin{array}{l}\text { Specific Ammonia } \\
\text { Utilization Rate }\end{array}$ & $\frac{\mathrm{mg} \mathrm{NH}_{3}}{\text { MLVSS}_{-}}$ & 0.81 & $9.50 \mathrm{E}-03$ & $1.14 \mathrm{E}-02$ \\
\hline $\begin{array}{l}\text { Specific Nitrate } \\
\text { Utilization Rate }\end{array}$ & $\frac{\mathrm{mg} \mathrm{NO}_{3}}{\text { MLVSS-d }}$ & 0.045 & $6.64 \mathrm{E}-03$ & 4.70E-04 \\
\hline $\begin{array}{l}\text { Specific BOD } \\
\text { Utilization Rate }\end{array}$ & $\frac{\mathrm{mg} \mathrm{BOD}_{5}}{\mathrm{gMLVSS}^{-} \mathrm{hr}}$ & $3-8$ & 1.2 & $9.50 \mathrm{E}-01$ \\
\hline $\mathrm{OP}(\% \mathrm{R})$ & & 10 & 18 & 88 \\
\hline
\end{tabular}

\subsubsection{High biomass process}

The MBR system requires a high biomass concentration MLSS > 7,000 mg/l) in order for the membranes to operate optimally. In addition, the high biomass operation results in smaller tanks volumes and a smaller over-all footprint for the system. Using MBRs to treat a medium to weak strength municipal wastewater requires the system to operate at low specific activities and low food-to-mass $(\mathrm{F} / \mathrm{M})$ ratios. Table 4 compares the average operational parameters and specific activities (BOD, nitrification, denitrification) for a high biomass MBR system with a conventional activated sludge BNR system. As can be seen the average $\mathrm{F} / \mathrm{M}$ and activities are 1 to 2 orders of magnitude lower for the MBR system. In addition, due to flux limitations inherent in the MBR system and low BOD of the 
wastewater, it is difficult to increase the F/M by increasing BOD load. The combination of low influent BOD (primary effluent BOD $=100 \mathrm{mg} / \mathrm{l}$ ), high biomass and low specific activity of the MBR system results in a system that is sensitive to small changes in water quality and environmental conditions.

\subsubsection{Temperature effects}

The performance of the MBR pilot system was heavily influenced by weather. During warm weather months, the MBR system experienced a biological foaming event that resulted in reduced membrane flux and residual membrane fouling as depicted in Figure 3. The foaming event occurred due to the low F/M ratio of the system caused by high specific activities resulting from the increase in water temperature and lower influent BOD indicative of summer wastewater flows. To overcome the foaming, the level in the MBR system was dropped to decrease hydraulic retention time by approximately $15 \%$, the biomass concentrations were dropped by approximately 30\%, and the flux was increased from $14 \mathrm{gpm}$ to $18 \mathrm{gpm}$ (max. flux). The foaming problem was brought under control, however there was a residual impact on the membranes that results in a $23 \%$ decrease in permeability. In addition, the average vacuum pressure for the system increased due to residual membrane fouling. However, the MBR system did continue to produce a high quality effluent during this period.

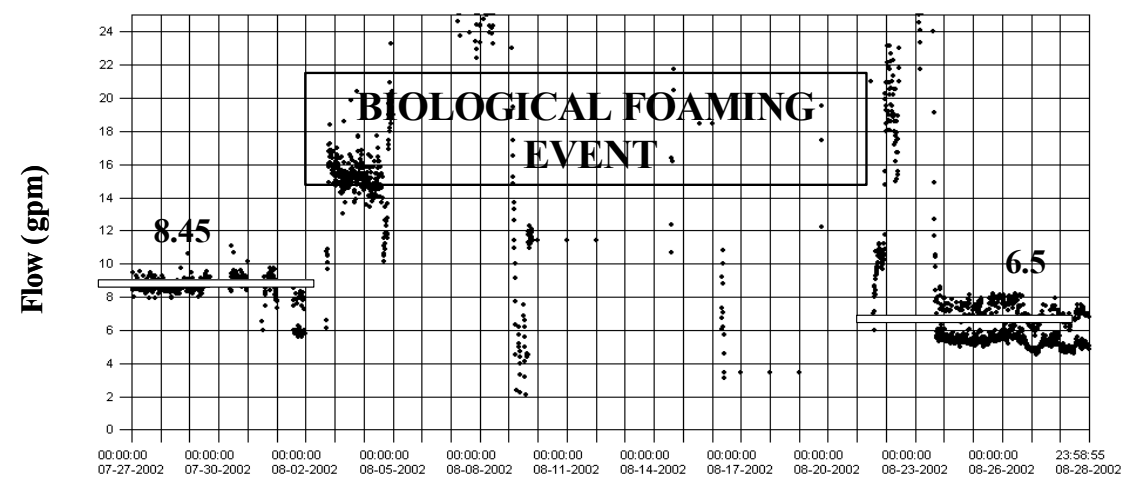

Time (days)

Figure 3: Reduction in membrane flux due to biological foaming event.

The membrane performance and the over-all performance of the MBR were affected by the cold weather. As can be seen in Figure 4, the membrane performance was very erratic and there was a non-biological foaming event. In addition, the rates of nitrification and denitrification decreased resulting in high ammonia and total nitrogen in the effluent. The causes for these effects were likely due to the cold temperatures $(5-6$ degrees $C)$ reducing biological activity and increasing the viscosity of the water, which impacted membrane performance. The impact of the severe cold weather included acute membrane fouling associated with extensive biomass loss (MLSS $<3,500 \mathrm{mg} / \mathrm{l}$ ). A residual 
impact was an increase in applied vacuum pressure to maintain a constant flux. It is believed that the cold weather foaming event was caused by biological products associated with biomass decay. The issue was dealt with by decreasing the HRT, increasing membrane flux, and decreasing SRT. Once the membranes were cleaned they performed as they did when the study began. Although it is likely that the pilot was more susceptible to temperature variations than a fullscale plant would be, it was apparent that when combined with low influent BOD concentrations, small changes in temperature did impact the performance of the system. These results demonstrate the need for keen operational control of BNR MBR plants, especially under conditions where the activity of the concentrated biomass can be altered significantly.

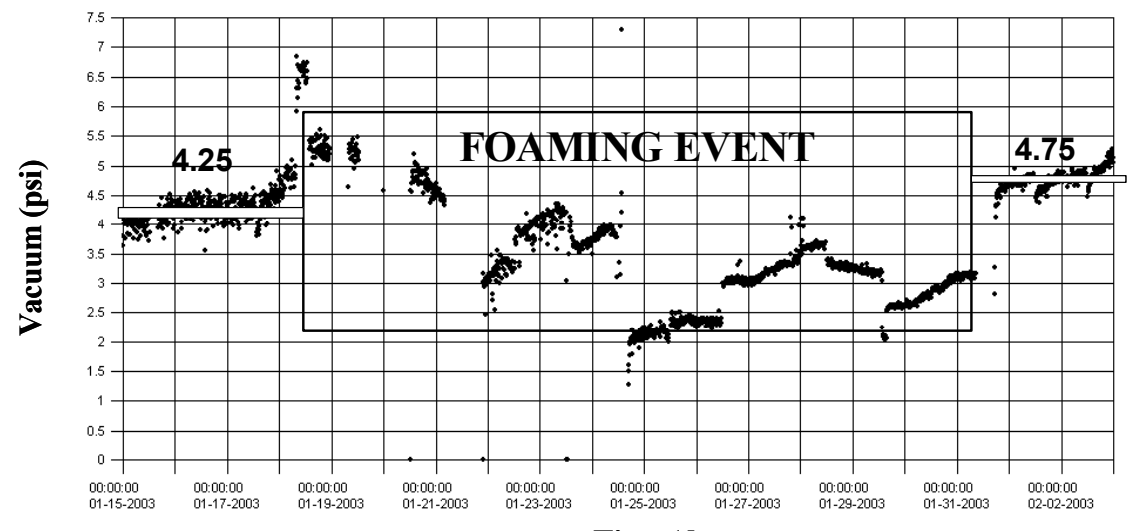

Time (days)

Figure 4: $\quad$ Impact of cold weather on membrane performance.

\subsubsection{Coagulant effects}

The impact of ferric chloride on membrane performance was not as obvious in the pilot study as it was in the bench-top study. In general, residual ferric chloride had no significant impact on membrane performance. There was a slight improvement in membrane performance that occurred after ferric chloride addition began which resulted in a $10 \%$ reduction in applied vacuum pressure and a $20 \%$ increase in flux.

\section{Conclusions}

The scale-up study presented here demonstrates four major conclusions regarding the impacts of coagulation on MBR systems and the applicability of MBR systems to effectively treat low strength municipal wastewater to reuse standards. These conclusions are:

1. Residual coagulant can enhances membrane performance.

2. The high biomass nature of the MBR system requires specific operational and process controls to balance membrane performance and effective treatment of low strength wastewaters. 
3. The membrane system was extremely flexible and resilient.

4. The MBR system was able to meet stringent reuse standards.

\section{Acknowledgements}

The authors acknowledge the support of the New York Energy Research and Development Authority, Rockland County, United Water, and Zenon.

\section{References}

[1] Crull, A.; Hooker, D., The rising tide. Water \& Wastewater Prod, 3, 2, 2002.

[2] Asano, T., Wastewater Reclamation and Reuse. Technomic, PA USA, 1998

[3] Ogoshi, M.; Suzuki, Y.; Asano, T. (2001) Water reuse in Japan. Water Sci. Technol., 43 (10), 17-23, 2001

[4] Diaper, C.; Jefferson, B.; Parsons, S.A.; and Judd, S.J., Water-recycling technologies in the UK. J. CIWEM, 15, 282, 2001

[5] Walker-Coleman, L., Reclaimed water rates in Florida. Proc. Water Reuse Assoc. Symp. XVI, [CD-ROM], San Diego, CA, 2001.

[6] Lazarus, J.; Drake, P. G. (2001) Water Reuse -Water quality and water rights Considerations. Online Source: http://www.unesco.org.uyphi/libros /efficient water/wlazarus.html.

[7] U.S. Environmental Protection Agency, Manual: Guidelines for Water Reuse EPA/625/R-92/004, 1993.

[8] Daigger, G.T. Biological nutrient removal. Online Source: http://ce.ecn.purdue.edu/ alleman/w3-class/456/article/daiggernutrients/ daigger.html.

[9] Freeman, S. et al., Membranes for water reclamation - present and future trends. Proc. Water Environ. Fed. $74^{\text {th }}$ Annu. Conf. Exp., Atlanta, GA, 2001

[10] Husain, H., Immersed in its work. Water \& Wastewater Prod., 2(5),52. 2002.

[11] Cote, P. Using your membrane: immersed ultrafiltration membranes an alternative to traditional water processes. Wat. \& Wastewat. Prod.. 2, (3), 38, 2001.

[12] Fleischer, E.J.; et al., Evaluating the next generation of water reclamation processes. Proc. Water Environ. Fed. $74^{\text {th }}$ Annu. Conf. Exp. [CD-ROM], Atlanta, Georgia, 2001. 